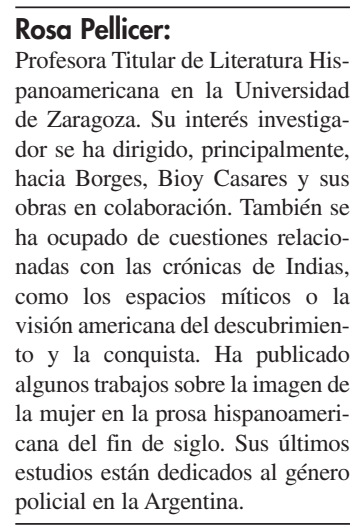

«[Esta obra] nos pone ante un hombre prejuicioso, como toda su época, imbuido de ideas teológicas y apriorísticas; y ante un erudito incansable. Como en todas las misceláneas coloniales - llámense «Miscelánea Austral» de Dávalos y Figueroa, o "Crónica Moralizada» de Calancha, - la Parte tercera inédita de las "Memorias antiguas y Nuevas del Perú» por el licenciado Montesinos- en ésta de León Pinelo se mezclan las más diversas materias». Luis Alberto Sánchez, «Don Antonio de León Pinelo, primer bibliógrafo americano», Boletín Bibliográfico. Biblioteca de la Universidad de San Marcos, 3:2 (septiembre 1928), pp. 220.

2

Isaías Lerner, «Saberes viajeros: las misceláneas y el Nuevo Mundo», en Juan José Perandones y otros (coord.), Universidad de León, Secretariado de Publicaciones, 2005, p. 19.

Dice Cabello Valboa refiriéndose a su libro: «le fue puesto á nuestra historia el nombre de Miscelánea, por la forzosa mixtura, de historias que consigo antecoge, al hilo de su proceder: que demas de ser lance forzoso el hacerlo (como bien veras) hermoseara mucho su discurso la mixtura de tantos colores》. Miguel Cabello Valboa, Miscelánea antártica. Una historia del Perú antiguo (1586), Instituto de Etnología (ed.), Lima, Universidad Nacional Mayor de San Marcos, 1951, p. 4.

3

José Luis Abellán, Historia crítica del pensamiento español. II. La Edad de Oro, Madrid, EspasaCalpe, 1979, p. 376.

Continens Paradisi: El Libro segundo de El Paraíso en el Nuevo Mundo de Antonio de León Pinelo ROSA PELLICER

\title{
CONTINENS PARADISI:
EL LIBRO SEGUNDO DE EL PARAÍSO
EN EL NUEVO MUNDO DE ANTONIO DE \\ CONTINENS PARADISI:
EL LIBRO SEGUNDO DE EL PARAÍSO
EN EL NUEVO MUNDO DE ANTONIO DE \\ CONTINENS PARADISI:
EL LIBRO SEGUNDO DE EL PARAÍSO
EN EL NUEVO MUNDO DE ANTONIO DE LEÓN PINELO
}

\author{
ROSA PELLICER \\ Universidad de Zaragoza
}

La idea de situar el Paraíso Terrenal en el Nuevo Mundo, aunque no fue de las más compartidas, tuvo algunos sustentadores, entre los que destacaron su descubridor, Cristóbal Colón y, ciento cincuenta años después, el primer bibliógrafo de las Indias Orientales y Occidentales, Antonio de León Pinelo. El título completo del libro es: El Paraíso en el Nuevo Mundo. Comentario apologético, historia natural y peregrina de las Indias Occidentales, Islas de Tierra Firme del mar Océano, que alude a formas historiográficas distintas como el «comentario» y la «historia». La cuestión genérica de El Paraíso en el Nuevo Mundo no parece resuelta y tampoco ha merecido demasiada atención por parte de sus escasos estudiosos, ya que no corresponde a ninguna de las tipologías establecidas para el discurso histórico. Tal vez, como sugirieron Luis Alberto Sánchez y su editor, Raúl Porras Barrenechea, se pueda calificar de «miscelánea», puesto que bajo el pretexto del comentario, anunciado en el título, recoge todo tipo de noticias raras y curiosas, "peregrinas», más o menos relacionadas con el tema de su apología ${ }^{1}$. Además, como señaló Lerner, en algunas ocasiones la historiografía adopta la estructura de las misceláneas, "ya que se adaptaba perfectamente a la inmensa variedad y a la diversidad y la abundancia de noticias contemporáneas». De este modo la obra de León Pinelo se situaría en la línea de otras misceláneas americanas o, mejor, peruanas, como la Miscelánea austral de Diego Dávalos y Figueroa, la Miscelánea antártica de Miguel Cabello Valboa, o la Crónica moralizada de Antonio de Calancha, bien conocidas y citadas por él ${ }^{2}$.

El Paraíso en el Nuevo Mundo es ante todo una obra de erudición. Como señala José Luis Abellán:

[León Pinelo] No da un paso sin apoyarse en alguna autoridad, sus citas son innumerables; su recopilación de documentos y bibliografía es incansable; y todo ello en medio de un estilo árido, seco y descolorido, que hace difícil su lectura ${ }^{3}$.

León Pinelo, como su amigo Juan Solórzano Pereyra, representan el final de un ciclo cultural, del que son su síntesis o depósito, como lo demuestran también sus tres publicaciones sobre la Recopilación de las Leyes de Indias (1629) o el Epitome de la biblioteca oriental y occidental, náutica y geográfica (1629). Nuestro autor no presenta un pensamiento original, por peregrina que sea tu tesis, ya que pertenece a un mundo de cultura jerarquizada y basada en la autorictas, el de la España católica de la contrarreforma, donde reina la teología de la segunda escolástica. No hay que olvidar que la erudición pasa a ser considerada no sólo adorno, sino método. Leemos en el Discurso LVIII de la Agudeza y arte de ingenio de Gracián: 
Cuanto más sublime y realzada fuere la erudición, será más estimada pero no ha de ser uniforme, ni homogénea, ni toda sacra, ni toda profana, ya la antigua, ya la moderna; una vez un dicho, otra un hecho; de la historia, de la poesía, que la hermosa variedad es punto de providencia4.

León Pinelo no tiene un sistema teórico, sino un método, que tiene que ver con el razonamiento casuístico, por "careo", que dice Gracián. La demostración de su tesis se desarrolla siempre en el mismo orden: exposición de la opinión, propia o ajena, argumentos a favor o en contra y, finalmente, aceptación o reprobación, es decir, «tesis, antítesis y síntesis» ${ }^{5}$.

Al comienzo del libro León Pinelo expone su propósito: «Yntento es y Qüestion principal deste Comentario investigar el Sitio y colegir el lugar que tuvo en su creación el Paraiso Terrenal: y si fue ó pudo ser en el Nuevo Mundo, que llamamos Yndias Occidentales, ó en alguna de sus Provincias» ${ }^{6}$. Después de casi novecientos folios, escritos bajo el signo de una erudición implacable y estéril, quedará demostrada su tesis: el Paraíso bíblico estuvo ubicado en América del Sur, en la parte que él llama la Ibérica Meridional, en los márgenes del Amazonas, y lo señala con absoluta exactitud en su detallado mapa del Paraíso, donde están presentes los árboles de la vida y del bien y del mal, así como el lugar donde se construyó el Arca de Noé y el punto de partida y dirección de su viaje. $E l$ Paraíso en el Nuevo Mundo está divido en dos partes: la primera corresponde al «comentario apologético» del Paraíso, el alma de la obra, una disquisición barroca sobre las diferentes opiniones a cerca de la localización del Jardín del Edén, y la demostración de su tesis; la segunda, el cuerpo y adorno, corresponde a la «historial natural y peregrina de las Indias», visión hiperbólica de su riqueza y grandeza?

Para el desarrollo de su tesis, lo primero que León Pinelo tiene que demostrar es la

\section{4}

Baltasar Gracián, Agudeza y arte de ingenio, II, Evaristo Correa Calderón (ed.), Madrid, Castalia, 1969, p. 218.

5

Señala Carlos Rey Pereira: "La construcción de unas series entraña una labor previa de recopilación de material y otra, posterior, de clasifica- existencia del Paraíso en la tierra, que «fue lugar corpóreo, real y verdadero", y todas las circunstancias descritas en el Génesis, explicadas por los comentaristas de la Escritura y los Santos Padres, que no son menos importantes. La distinción que hizo la patrística entre el Cielo, lugar propio de Dios, y el Paraíso terrenal permitió a teólogos, humanistas y artistas humanizar el otro mundo. La Edad de Oro y los Campos Elíseos de la mitología clásica se convirtieron en conceptos cristianos del más allá, a la vez que surgió el problema de la localización del Paraíso ${ }^{8}$. El Libro Primero está dedicado a confutar las diecisiete opiniones contrarias a su localización en el Nuevo Mundo; en la dieciocho, que desarrolla en el Libro Segundo, tratará de justificar la suya. Si nos parece un desatino el colocar el Jardín del Edén en la Ibérica Meridional, no parece menor el ubicarlo cerca del cielo de la Luna o en el monte Athos. La principal batalla la libra nuestro autor contra los que sostienen la existencia del Paraíso en regiones fuera de la Tierra; una vez ganada, refutar las hipótesis de que estuvo en otro lugar que no fuera la Ibérica, como en India, Mesopotamia, la isla de Taprobana, Palestina o el campo de Esledrón cercano a Damasco, es sencillo. La opinión que demostrará a lo largo del libro segundo es la siguiente:

La decima octava y ultima da por sitio al Parayso otro Continente de Tierra distinto y separado deste de Asia, Africa y Europa que habitamos. Y esta es la que pretendo seguir por antigua, y probar por moderna, verificandola en el Continente del Nuevo Mundo, y fundando esta opinión en sus terminos antiguos sin añadirle mas nobedad que la que han causado los Siglos con el descubrimiento de las Yndias Occidentales, le supone en ellas. (I, p. 4)

La primera dificultad es la localización del Jardín del Edén en un continente distinto al mundo conocido. En su auxilio acude, principalmente, San Efrén, que aunque percibió este

encontrado se organiza, fruto de una operación de síntesis, desmenuzándose de acuerdo a una red de categorías preestablecidas por el autor». Carlos Rey Pereira, El Paraíso en el Nuevo Mundo: entre el ejemplo y la excepción», Cuadernos para la Investigación de la Literatura Hispánica, 29 (2004), p. 146 Paraíso en el Nuevo Mundo, Raúl Porras Barrenechea (int y ed.), Lima, Comité del Bicentenario del Descubrimiento del Amazonas, 1943, vol. I, p. 1. En adelante sólo se indica el volumen y el número de página.
7

"Con que habremos concluido no solo el Comentario del paraíso, sino tambien la Historia na tural y peregrina de las Yndias, que es cuerpo de esta alma, ó adorno del cuerpo» (I, p. 125). Juan Larrea puso en relación la opinión de León Pinelo de América como continens Paradisi con su origen judío: "Afecto, como judío, por inclinación biológica, al orden material, presiente a semejanza de sus antepasados, una Tierra prometida. Como cristiano presiente la vida celeste prometida, en un orden espiritual. Como judío-cristiano realiza, pues, la síntesis amorosa de ambos términos en apariencia contradictorios, la solución de la antinomia materialismoespiritualismo, en una fórmula histórica cuya primera localización temporal es América». Juan Larrea, «El Paraíso en el Nuevo Mundo de Antonio de León Pinelo», España Peregrina, I, 8-9 (octubre 1940), p. 85.

8

Véase Coleen McDannell y Bernhard Lang, Historia del cielo, Madrid, Taurus, 1990. Para las diferentes versiones del Paraíso continúa siendo imprescindible el estudio de Arturo Graff, «Il mito del Paradiso Terrestre», en Miti, leggende e supersticiones, I, New York, Burt Franklin, 1971 (reimpresión). Ildefonse de Vuippens, en la primera parte de su libro, recorre las opiniones de los primeros cristianos. Su conclusión es la siguiente: «Selon cette tradition, c'est au paradis qu'on été transférés deux qui ont été enlevés de la terre (Énoch et Élie); c'est là qu'ils demeureront jusqu'à la fin des temps; c'est au paradis d'Adam que S. Paul a été ravi et qu'il a entendu des paroles inenarrables; c'est là même qu'a éte préparée la demeure des justes et des hommes doués de l'esprit. C'est également de la bouche des Anciennes qu'il apprit l'existence de trois séjours pour les élus après le jugement: le ciel lou plutôt le ciel des Vieux) pour les uns; les délices du paradis pour les autres et la gloire de la cité pour les derniers». Ildefonse de Vuippens, Le Paradis terrestre au troisième ciel. Exposé historique d'une conception chrétienne des premiers siècles, Paris- Fribourg, Librairie Saint François d'AssiseLibrairie de l'Oeuvre de S. Paul, 1925 , p. 30.
Continens Paradisi: El Libro segundo de El Paraíso en el Nuevo Mundo de Antonio de León Pinelo ROSA PELLICER 
9

Véase Graff, op.cit, pp. 4-5 y Howard R. Patch, El otro mundo en la literatura medieval, México, FCE, 1956, pp. 151 y 153.

10

Como señala su traductor y comentarista Francisco Javier Martínez Fernández: «Esta idea tiene sin duda un carácter polémico, en relación con quienes localizaban el Paraíso en un lugar de la tierra. Afirmaciones análogas se hallan en Comm. Gen. II,6 (refiriéndose a los ríos del Paraíso y su relación con los de la tierra), en la recensión occidental de CT III, 15 («el Paraíso rodea toda la tierra») y en Salomón de Bassora, El libro de la abeja, 19-20, que se refiere a esta tradición como una tradición alternativa a la que sitúa el Paraíso en el Este, mas allá del océano. En realidad, las dos tradiciones no son tan divergentes, y la segunda parece más bien un nuevo intento de traducir geográficamente afirmaciones teológicas como las de Efrén». (www.sanefren.es)

11

Teresa Gisbert describe el mapa: "León Pinelo, que cree interpretar adecuadamente a San Efrén, nos presenta un mapa del mundo muy esquemático, también desarrollado sobre un círculo [...] El continente único está dividido en tres sectores: Europa, África y Asia de acuerdo al esquema medieval, con la salvedad de que Asia, a su vez, ha sido dividida en Asia Menor y Asia Mayor, así el esquema tripartito europeo se transforma en un esquema cuatripartito, muy acorde con el pensamiento andino». (Teresa Gisbert, «León Pinelo y la imagen del Paraíso en los Andes", Anuario (Archivo y Biblioteca Nacionales de Bolivia (1996), p. 28. A esta última opinión cabría añadir que la división cuatripartita del mundo era la habitual en el siglo XVI. Por citar sólo dos ejemplos tanto en la Suma de geografía de Martín Fernández Enciso como en el Islario general de Alonso de Santa Cruz, la esfera terrestre queda dividida en dos hemisferios, el septentrional y el meridional divididos por la línea del Ecuador, y el meridiano cero, que la divide en dos partes iguales, la oriental y la occidental.

Continens Paradisi: El Libro segundo de El Paraíso en el Nuevo Mundo de Antonio de León Pinelo ROSA PELLICER

jardín en un sentido espiritual -«Con los ojos de la mente/ vi el Paraíso»-, las descripciones del Edén de sus Himnos sobre el Paraíso contribuyeron a otorgarle una historicidad evidente, y su intérprete Moisés Bar Cefas. Así, se llega a la conclusión de que el Paraíso se hallaba en un lugar muy elevado y estaba «no en este continente, sino en otro distinto, separado y apartado»9. Raúl Porras Barrenechea resume la opinión de Bar Cefas:

El Bar Cefas (el hijo de Cefas) sostiene que el Paraíso fue tierra diferente de la occidental en naturaleza y en calidad, que estaba en medio del mar, rodeada de montes inaccesibles, en aguas no navegadas por ningún hombre y que el Océano primero y el Paraíso después de éste, rodeaban como dos círculos concéntricos el mundo conocido. (I, p. XXXIII)

León Pinelo interpreta a San Efrén en su mapa del mundo, muy esquemático, que corresponde a un pensamiento medieval. Desarrollado en un círculo se muestra a América, dividida en dos partes, como un anillo externo que rodea al viejo continente. Leemos en el primero de los Himnos sobre el Paraíso de San Efrén:

En ese halo que se forma

alrededor de la luna

veamos el Paraíso:

así también él rodea

mar y tierra,

que están como encerrados dentro de él ${ }^{10}$.

Aunque León Pinelo sabe que el mundo no es plano, tiene que adoptar este esquema para adecuarse a la cosmografía de los Padres de la Iglesia, en la cual la tierra conocida forma un único continente rodeado por las aguas, y más allá de éstas se encuentra el Paraíso ${ }^{11}$.

Después de concluir que el Paraíso «fue un lugar real y verdadero», y que estuvo en otro continente, a pesar de las lecturas simbólicas

12

A pesar de sus dudas escribe el Padre Acosta: "Si guiaran su opinión por aquí, los que dicen que el Paraíso Terrenal está debajo de la Equinoccial, aun parece que llevaran camino, no porque me determine yo a que está allí el Paraíso de Deleites que dice la Escritura, pues seria temeridad afirmar eso por cosa cierta. Mas dígolo porque si algún paraíso se puede decir en la tierra es donde se goza de un temple tan suave y apacible». José de Acosta, Historia natural y moral de las Indias, José Alcina Franch (ed.), Madrid, Historia 16, 1986, p. 150.

13

Señala Delumeau que: «A lo largo de los siglos XVII y XVIII se le atribuyeron al paraíso

del propio San Efrén, tiene que demostrar que se encuentra en Occidente, no en Oriente como señalan el Génesis y los Padres de la Iglesia, pero también Pierre d'Ailly y los mapas medievales. Nuestro obstinado autor arguye que la Escritura dijo únicamente que se hallaba situado al Oriente de la tierra donde vivió Adán; por tanto, debe referirse a «las Regiones más orientales que respecto del Orbe habitable se hallaren». Tampoco podía estar muy cerca, en Palestina o Mesopotamia, porque entonces no se hubiera perdido su memoria; además, no sabemos cuál era la situación de Moisés al hablar de Oriente. A lo anterior se suma la hipótesis «ecuatorial», que aparece en Tertuliano, Santo Tomás de Aquino y San Buenaventura, que cobró fuerza con la localización de Colón en la zona equinoccial, ya que el golfo de Paria sería el camino que llevaba al Paraíso terrenal ${ }^{12}$. Escribe León Pinelo en uno de los escasísimos momentos de inspiración poética:

Es el sitio de la Equinoccial donde quiera que se convide el mas calificado y preheminente por naturaleza de todos los del Mundo. En el no se mudan los tiempos, son siempre iguales los días y las noches, ellas con la frescura que basta, ellos con el calor que conserba el perpetuo berdor de las Plantas, en continua hermosura los Campos, sin que el frío los marchite ni el rigor los agoste. Antes en eterno Verano y nunca acabada Primavera son Retratos todo el año del Terrenal Paraíso. (I, p. 38)

Como señala Jean Delumeau, esta hipótesis, también sostenida por Simao de Vasconcelos en su Cronica da Companhia de Jesus (1663) que lo situaba en Brasil, fue rechazada por los comentaristas del Génesis de los siglos XVI y XVII, ya que había que tener en cuenta que el texto sagrado situaba el Jardín del Edén al Este, y mencionaba el Tigris y el Eúfrates ${ }^{13}$.

tres localizaciones distintas, entre las cuales se repartieron las opiniones de los mejores comentaristas del Génesis: Armenia, Mesopotamia y Tierra Santa. Las opiniones casi fueron unánimes a considerar que era necesario reemplazar el a principio de la Vulgata, por ab Oriente, y por lo tanto sustivir plataverat autem Deus paraisum voluptatis a principio (Génesis 2:8) por platavit Deus hortum ab Oriente. Tal era el sentido que la Septuagina y los padres griegos, entre otros, habían dado a ese pasaje [...] Un paraíso cuya localización estuviera en América o en África se encontraba, por lo tanto, eliminado». Jean Delumeau, Historia del Paraíso. 1.

El Jardín de las delicias, Segio Ugalde Quintana (trad.), Madrid, Taurus, 2005, p. 294. 
Una vez superada la dificultad geográfica, le quedaba a León Pinelo otra aún mayor, la histórica. Dado que el Jardín del Edén se encuentra en América, no en vano tiene forma de corazón, y el hombre primigenio procede de allí, la cuestión principal es solucionar cómo pasó a poblarse el mundo conocido, y cómo se repobló el nuevo. Es en el Libro segundo donde León Pinelo dedica sus esfuerzos a fundamentar su tesis del origen del hombre, en la que tiene una importancia fundamental Noé y su arca.

Para Antonio de León Pinelo el hombre tuvo su origen en América, puesto que Dios lo puso en el Edén después de su creación, y hemos visto que el Jardín de Deleite y el Edén acaban por identificarse. Después de la expulsión, Adán y Eva no pudieron ir muy lejos, así que se quedaron en sus márgenes y poblaron en lugares cercanos. En su mapa del Paraíso, además de destacar los cuatro grandes ríos, la región correspondiente al norte de Brasil, Colombia y Venezuela se rotula como Habitatio filiorum hominum y la costa del $\mathrm{Pa}-$ cifico Habitatio filorum Dei. En la región que corresponde al Perú actual aparece el arca de Noé y el camino que emprendió en tiempos del diluvio. La división de los hombres corresponde al Génesis, que llama «hijos de los dioses» a los descendientes de Set, el «pueblo de Dios», e «hijos de los hombres» a los de Caín, que fue expulsado a las tierras al oriente del Edén. Noé, perteneciente a la décima generación de Adán, fabricó su arca de cedros, y en su navegación llegó a otro continente, que estuvo deshabitado hasta que encalló en los montes de Armenia, de modo que América quedó despoblada. Amparándose en la autoridad de Bar Cefas, Pinelo expone al comienzo del Libro segundo su propia opinión:

Dice pues que desde la expulsión de Adán, quando fue arrojado del Paraiso hasta la universal inundación de la Tierra, todos sus descendientes habitaron aquella, ó aquel Continente ultramarino: y que todo el tiempo que pasó hasta el Diluvio, que fue de mil seiscientos cincuenta y dos años, estuvo deshabitado $\mathrm{y}$ sin persona humana este que ahora habitamos; $\mathrm{y}$ que como con las aguas perecieron todos los hombres excepto Noé y su Familia, haviendo fabricado el Arca que Dios le mandó de los Cedros que había plantado entró en ella y fue conducida del Espíritu Santo por encima de las aguas, desde aquella Tierra o Continente del Paraiso a este en que se conserva su descendencia. (I, pp. 118-119)
Para León Pinelo la población americana tiene un doble origen: antes y después del Diluvio, que necesariamente fue «universal», ya que se perdió la noticia del Paraíso. Esta tesis invierte el orden habitual que presentan las hipótesis de los siglos XVI y XVII, por desatinadas que sean, de las que dan cuentan tanto las misceláneas y El Paraíso en el Nuevo Mundo, como los libros de Gregorio García o de Diego Andrés Rocha, que no pudo acoger la del origen inverso propuesta por León $\mathrm{Pi}$ nelo, dado que su libro quedó manuscrito ${ }^{14}$.

Antes de continuar quizá sea necesario, o por lo menos curioso, hacer una digresión sobre algunas opiniones en torno al origen de los pueblos americanos, de las que se ocupa nuestro apologista, para refutarlas con las armas de la erudición y del sofisma. Desde el comienzo, el descubrimiento del Nuevo Mundo planteó el problema del origen del hombre americano y muy pronto surgieron multitud de hipótesis para explicarlo. Al lado de opiniones disparatadas sobre la cuestión, aparecieron también otras más sensatas, como la formulada por el Padre Acosta. Ahora sólo nos interesan las que tienen que ver con un origen mediterráneo o bíblico, porque era fundamental demostrar que los habitantes del Nuevo Mundo eran también descendientes de Adán y Eva, de otro modo se podría creer que no se trataba de verdaderos hombres ${ }^{15}$.

En relación con el origen judío, la primera partió de Colón al identificar Haití con el bíblico Ofir; más tarde la filología vino a corroborar la identidad de los nombres de Ofir y Perú. Esta teoría, sostenida por Benito Arias Montano, tuvo una gran difusión y aceptación. Para este humanista Ofir, hijo de Jectán, nieto de Heber, pobló América hasta el Perú, habiendo entrado por el noroeste, mientras, Jobal, poblaba el Brasil. Miguel Cabello Valboa dedica su Miscelánea antártica a demostrar que el origen de los indios occidentales era el «Patriarca Ophir, hijo de Iectan, quarto hijo de Sem, primero de Noé». Bajo este presupuesto la comenzó a escribir en 1576, animado por la autoridad de Arias Montano, expuesta en el «primer volumen de el aparato de la Sacra Biblia Real». La estructura de esta miscelánea es semejante a la de León Pinelo: el primer libro está dedicado a la creación del mundo, el diluvio y la división de la Tierra entre los descendientes de Noé; el segundo a las causas del olvido de los antiguos pobladores de estas historias y y el tercero,

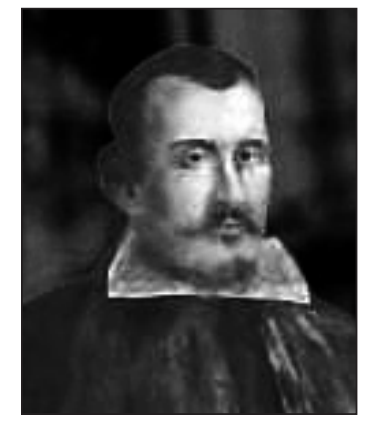

Antonio de León Pinelo.

14

José Imbelloni menciona como precursores de esta idea a Brasseur de Boubourg, y a Auguste Le Plongeon, que en siglo XIX sostenían que la cultura egipcia fue un trasplante en tierras africanas de las civilizaciones de Centro América, y que, aplicándola a los sumerios, sostuvo Clemente Ricci. José Imbelloni, La segun da esfinge indiana. Antiguos y nuevos aspectos del problema de los orígenes americanos, Buenos Aires, Hachette, 1956, pp. 6778. Por su parte el argentino Florentino Ameghino «elaboró una complejísima teoría según la cual el hombre había surgido en América, y más concretamente en Argentina» Historia de Iberoamérica. I. Prehistoria e historia antigua, Manuel Lucena Salmoral (coord.), Madrid, Cátedra, 1987 , p. 23.

15

Como señala Luis Pericot: «Para los escritores católicos, intérpretes de la Biblia con criterio muy estricto entonces, era tarea importante el probar que los americanos descendían también de Adán y Eva y pertenecían, por tanto, a la misma creación que los restantes hombres, $y$, al mismo tiempo, que descendían de Noé, habiéndose diferenciado después de éste al poblar sus hijos todo el Universo. De no admitirse esto, se caería en lo que se cayó por algunos, o sea en no considerarlos seres iguales al resto de los humanos. Esta preocupación explica en parte muchas de las ideas que se defendieron entonces». Luis Pericot y García, America indígena. 1. El hombre americano. Los pueblos de América, Barcelona Salvat, 1936, p. 362.

Continens Paradisi: El Libro segundo de El Paraíso en el Nuevo Mundo de Antonio de León Pinelo ROSA PELLICER 
16

Cabello Valboa, op.cit., pp. 4 y 8.

17

«Éstos de nuestras Indias, se tiene por más cierto que se originaron por la mayor parte de la oriental o de alguna redundancia de chinas y tártaros; y así Arias Montano los llamo "ofiritas» y quiere que desciendan de los dos hijos de lectán, Ofir y Hevila, que fueron los pobladores de ella $Y$ de verdad es mucha la semejanza que hay entre los de ambas Indias en talles, condiciones, ritos y costumbres, y especialmente en el color de membrillo cocho, como lo consideran otros, dando las causas de él, y de los negros y su cabello crespo, pero haciéndolos a unos y otros descendientes de Cam, hijo de Noe, y que por haber incurrido en la maldición que él les echó cuando descubrió su embriaguez padecen éste y otros trabajos y servidumbres y se han quedado por la mayor parte de mediana estatura». Juan Solórzano Pereyra, Política Indiana, (1647) I, pról. Francisco Tomás y Valiente, Fc. Tomás y Valiente y Ana $M^{a}$ Barrero (eds.) Madrid, Turner, "Biblioteca de Castro», 1996, p. 70.

18

Pedro Sarmiento de Gamboa, Historia de los Incas, Madrid, Ediciones Miraguano/Ediciones Polifemo, 2008, p. 35. Diego Dávalos y Figueroa, a pesar de la opinión de Acosta, piensa al respecto: "Pero si acaso fue assi que esta ysla vuiesse sido en algun tiempo, digo que el agua que la anego asta de ser del mar del Sur, y romper por el estrecho que llamamos de Magallanes, assi porque no sabemos de cierto otra parte por donde se comuniquen estos mares, como porque paresce, a quien bien lo considera, que el mar del Sur está mas alto que el Oceano que es el del Norte, donde dizen estaua esta ysla». Diego Dávalos y Figueroa, Priemera parte de la Miscelánea austral (1602), Colección Clásicos Tavera, serie II, vol. 2, Textos Clásicos de Poesía Virreinal, 2001, p. 144

\section{9}

Diego Andrés Rocha, El origen de los indios, José Alcina Franch (ed.), Madrid, Historia 16, 1988, p. 122. Una de las tesis de Rocha es que los indígenas americanos tímidos son los descendientes de las diez tribus de Israel, y los valerosos de los españoles.

Continens Paradisi: El Libro segundo de El Paraíso en el Nuevo Mundo de Antonio de León Pinelo ROSA PELLICER

que enlaza con el primero, se ocupa de «los originarios padres de estos Indios hicieron en este pedazo del Mundo (vacio asta aquellos tiempos) y de q' manera, con que orden, en q'creencias se sustentaron en el: asta que comenzaron los Reies Ingas á eregir Imperio en este gran Reino de Piru cuias Historias te presento delante mas verdaderas y copiosas que jamas han salido a luz» ${ }^{16}$.

Esta opinión, bien que con matizaciones, fue aceptada incluso por Juan Solórzano Pereyra, amigo de Pinelo, que piensa que al Nuevo Mundo pudieron pasar hombres y animales por tierra, a nado o en embarcaciones pequeñas, ya que hay numerosas islas y estrechos al lado de los continentes, que servirían de "gradas», pudiendo así comunicarse los dos ${ }^{17}$.

La hipótesis de que los indios americanos proceden de la Atlántida también tuvo varios seguidores. Podemos recordar a Pedro Sarmiento de Gamboa (1572), que partiendo del linaje de Noé, «segundo padre general de los mortales», cree que a uno de sus nietos, Atlas, hijo de Neptuno, le correspondió en el reparto de la tierra la isla Atlántica, que luego desapareció debido a un gran cataclismo:

Estos y sus descendientes reinaron muchos siglos allí, señoreando por la mar otras muchas islas, las cuales no podían ser otras sino las de Haití, que llamado Santo Domingo y Cuba y sus comarcanas, que también serían pobladas de los naturales de esta isla Atlántica ${ }^{18}$.

La procedencia española de los primeros pobladores de las Indias occidentales ya fue sostenida por Gonzalo Fernández de Oviedo, que los hacía descender del rey Hespero y es suficientemente conocida. Casi ciento cincuenta años después, Diego Andrés Rocha, en su Tratado único y singular del origen de los indios del Perú hace compatible la tesis de Oviedo con la de la descendencia de las diez tribus perdidas de Israel:

Yo tengo por cierto que muchos de estos indios occidentales descienden de las diez tribus que desterró

20

«El segundo fundamento que habemos de suponer es que las gentes que hay en las Indias, a quien llamamos indios, fueron a ellas de una de las tres partes del mundo conocidas: Europa, Asia y
África. La razón de aquesto es, porque si al principio del mundo después del diluvio en tiempo de Noé y sus hijos - nietos fuera poblada la cuarta parte llamada América, hubiera noticia de ella e hicieran mención los antiguos

Salmanasar, y que entraron y poblaron esta América por las costas de Méjico, por el reino de Anian; pero tenía ya esta América desde el tiempo de Tubal y de Hespero y de los cartagineses mucha gente que vinieron poblando la parte del Norte, saliendo todos de España ${ }^{19}$.

Por su parte, Gregorio García en Origen de los indios del Nuevo Mundo e Indias Occidentales (1607), muy bien conocido por León Pinelo, resume once pareceres sobre el problema, partiendo de la premisa de que deben proceder de Europa, Asia o África ${ }^{20}$. Así, además de las teorías mencionadas, da cuenta del origen cartaginés, romano, español pero posterior al Imperio Romano, fenicio, griego, chino o tártaro. Con Diego Andrés Rocha, Gregorio García defendió el paso de los españoles al Nuevo Mundo en época de Tubal, hijo de Jafet, de modo que el origen remoto de los indios es el mismo que el de sus descubridores. A pesar de la resistencia a exponer su propia opinión, acaba por no decantarse por ninguna y aceptar que provinieron de todos los pueblos enumerados. De modo que por un lado se niega la historia americana y por otro ésta se convierte en un reflejo de la europea.

José de Acosta sostuvo que los pobladores de América provenían de Asia, no del arco mediterráneo; una idea poco habitual en su tiempo, ya que no se conocía la existencia del estrecho de Bering. A diferencia de otros especuladores, Acosta se guía por el «hilo de la razón, aunque sea delgado", y piensa que hubo varias formas posibles de que los indios llegaran al Perú: por mar o por tierra; si fue por mar, por azar o por voluntad. Una vez examinadas concluye que

se ha de decir que pasaron no tanto navegando por mar como caminando por tierra. Y este camino lo hicieron muy sin pensar mudando sitios y tierras su poco a poco, y unos poblando las ya halladas, otros buscando otras de nuevo, vinieron por discurso de tiempo a henchir las tierras de Indias de tantas naciones y gentes y lenguas ${ }^{21}$.

historiadores y cosmógrafos como la hicieron de las tres partes ya nombradas». Gregorio García, Origen de los indios del Nuevo Mundo e Indias Occidentales, C. Baciero y otros (eds.), Madrid C.S.I.C., 2005, pp. 68-69.
21

José de Acosta, Historia natural y moral de las Indias (1590), José Alcina Franch (ed.), Madrid, Historia 16, 1987, p. 114. 
Frente a tantas hipótesis desatinadas y la imposibilidad de saber a ciencia cierta cuál fue origen de la población americana, aunque acercándose a la hipótesis de Acosta, el Inca Garcilaso de la Vega prefiere dejar de lado el problema: «Y porque en cosas tan inciertas es perdido el trabajo que se gasta en quererlas saber, las dejaré, porque tengo menos suficiencia que otro para inquirirlas» ${ }^{22}$.

El denominador común a las diversas opiniones sobre el origen de los indios occidentales, ya que es necesario tener en cuenta las Escrituras, es que América estuvo deshabitada antes del Diluvio, y que se pobló después de él. Frente a lo establecido, León Pinelo argumenta con una opinión contraria. Como hemos visto, después de demostrar que los hombres hasta el diluvio habitaron el continente donde había estado el Paraíso, que allí fue fabricada el Arca y que ésta, guiada por el Espíritu Santo, navegó por encima de las tierras inundadas con los ángeles por marineros, por lo que no pudo sufrir ningún percance, hasta encallar en los montes de Armenia, nuestro autor pasa en el capítulo VII del Libro segundo a un argumento más «práctico y material»: la capacidad y forma del arca, de la que proporciona la descripción de los pisos y «mansiones», de acuerdo a las instrucciones dadas por el Espíritu Santo a su constructor. Después de complicadísimos cálculos, concluye que el Arca fue una «Nave ó Galera», que «tuvo veinte y ocho mil ciento veinte y cinco toneladas» (I, p. 174), y que pudo transportar:

tres millones trescientas y setenta y cien mil arrovas, ó cincuenta y seis mil doscientas y cincuenta Pipas ó Caxas equivalentes. Y esto sin la gente que fuese menester para su porte y grandeza a ser Galeón [...] Y si el Arca tenía el tamaño referido, que no es dudable, y era equivalente a catorce Naos destas mayores, catorce mil personas podía conducir demas de las Toneladas que le señalamos. (I, p. 174)

Nuestro autor también nos proporciona unas tablas cronológicas del diluvio universal y del viaje de Noé, para concluir que el viaje comenzó, según el calendario juliano, el domingo 28 de noviembre de 1656 desde la creación del mundo, y terminó el 27 de noviembre de 1657 cuando Noé salió del Arca. El viaje tuvo que ser de Oriente a Occidente, el más misterioso por ser el símbolo de la muerte, y el itinerario fue el siguiente: partió

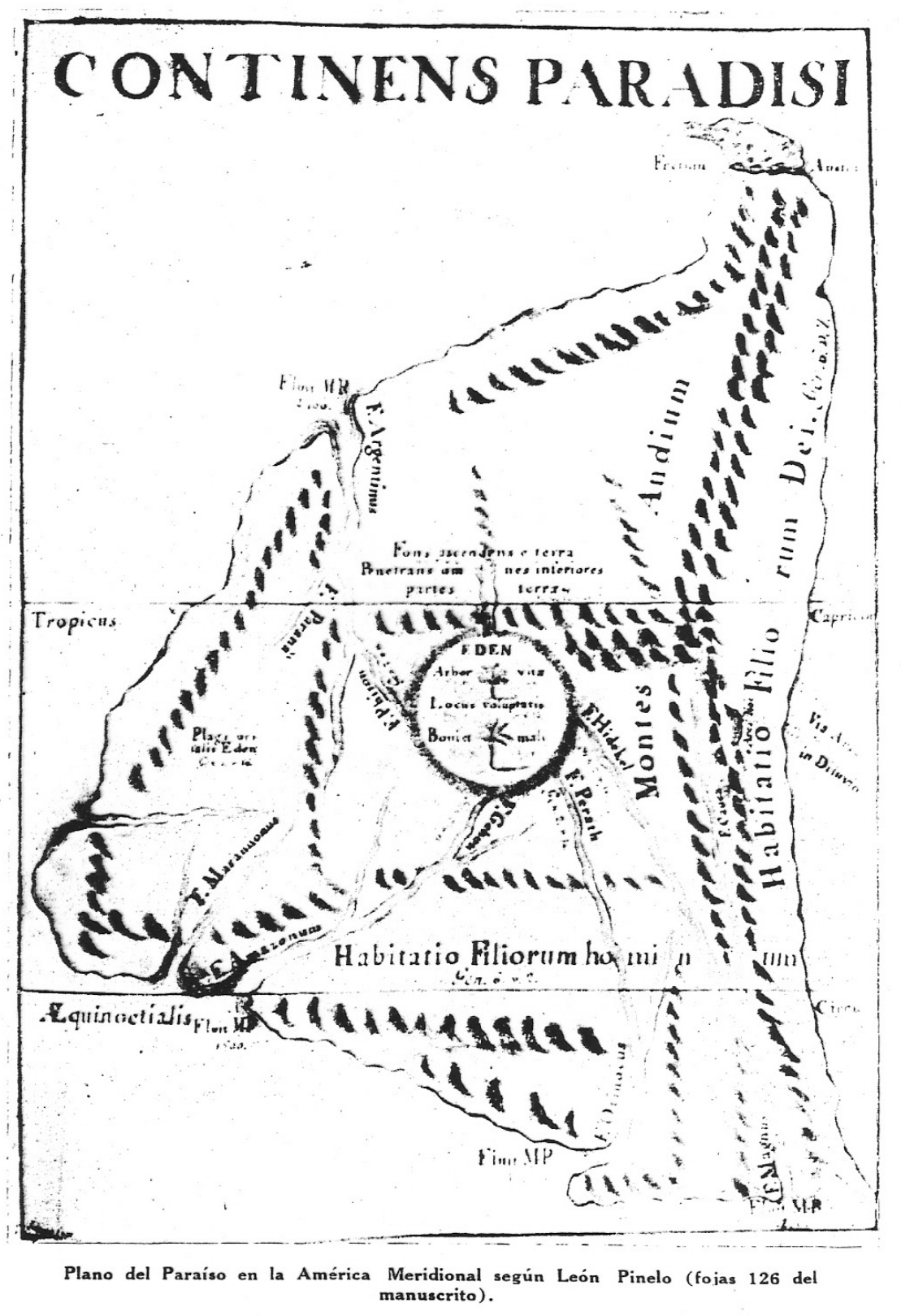

de la cordillera de los Andes, en el noveno día del Diluvio, hacia el Océano Pacífico, luego viró un poco hacia el norte y entró en el continente asiático, entre la isla de Corea y la punta de la China, siguió por el lago Cincun Hay, el Ganges, encallando finalmente junto al monte Naugracot, que tiene la misma latitud y longitud que el Paronaniso, es decir, el Cáucaso. Recorrió una distancia de 3605 leguas, más o menos una legua a la hora, lo que se ajusta al cómputo de horas y leguas y al tamaño del Arca. Como comenta Larrea, «el mito se ha organizado con voluntad de exactitud científica. El amor todo lo puede» ${ }^{23}$. Este viaje a Occidente continuó más tarde en la expansión del Evangelio, culminando con el
22

Inca Garcilaso de la Vega, Co mentarios reales de los Incas, I, Aurelio Miró Quesada (ed.), Caracas, Ayacucho, 1985, p. 12. 23 J. Larrea, art. cit., p. 78.

Continens Paradisi: El Libro segundo de El Paraíso en el Nuevo Mundo de Antonio de León Pinelo ROSA PELLICER 
24

San Efrén, Comentario, pp. 92 93

25

Dice Luis Alberto Sánchez al respecto: "Desde luego, la enunciación de éstas que en realidad podemos llamar "teorías» de León Pinelo, coloca a su autor en un plano bastante más elevado que la generalidad de los cronistas, porque establece la posibilidad, si no la vehemente sospecha, de la existencia de una civilización, no ya antediluviana, sino simplemente preincaica». Luis Alberto Sánchez, art. cit., p. 222.

26

Esta idea se repite a lo largo del texto. Sólo un ejemplo: »dejamos probado, que en terminos rigurosos de Geografía, la India que por antonomasia llamamos Oriental, no lo es respecto del sitio en que Moisés escribió la sagrada Historia del Paraíso. Con ya por esta calidad se hallan totalmente excluidas aquellas Regiones de la pretensión en que concurren. También hemos probado(a) que las Indias a que damos el nombre de Occidentales respecto de España son Orientales respecto de Indias i del sitio que para esta regulación se debe señalar, con que sin salir de este primer argumento antes valiendonos se reconoce claramente, que nuestra Indias se prefieren a las Orientales en la composicion del Orbe, para que se les deba atribuir el Paraiso». (II, p. 2).

Continens Paradisi: El Libro segundo de El Paraíso en el Nuevo Mundo de Antonio de León Pinelo ROSA PELLICER descubrimiento de las Indias Occidentales, y cerrando el círculo.

La existencia de hombres antediluvianos en las Indias Occidentales queda demostrada por la memoria constante que ha quedado de ellos. Una buena prueba es la existencia de gigantes, de los que habla el Génesis, mencionados por numerosos autores modernos, entre ellos Diego Dávalos y Figueroa. El comentario de San Efrén es el siguiente:

Después de estas cosas [Moisés] escribió sobre las descendencias que tuvieron las hijas de Caín con los hijos de Set y dijo así: Que bubo gigantes en aquellos dias y también después, porque entraron los jueces a las hijas de los hombres y se engendraron los gigantes del mundo, gigantes renombrados (Gen. 6.4). Los gigantes que nacieron del exiguo linaje de la casa de Caín, y no de la fuerte casa de Set. (...) Los hijos de Set, puesto que eran hijos de la bendición, vivían en la tierra que está al lado de la cerca del paraíso y sus productos eran abundantes y robustos, y de este modo los cuerpos de los que comían eran fuertes y rollizos ${ }^{24}$.

Además de los restos de huesos encontrados, sirve como argumento las grandes obras y edificios, de los que León Pinelo da cumplida cuenta, a la vez que adelanta la segunda parte de su libro. Las razones que da para demostrar que las grandes construcciones, o sus ruinas, no pudieron realizarlas los indios, radican en que éstos carecieron de instrumentos y habilidad, además de no conservar memoria de ellas. Después de la habitual exposición de teorías y reprobaciones, León Pinelo concluye sin ningún asomo de duda:

Porque si el Nuevo Mundo estubo poblado antes del diluvio, es evidente que en el fue el Paraiso: pues a ser en este no pasarían los hombres en aquella edad a poblarle, surcando tan peligrosos Mares, quando está en duda que navegasen los mas pequeños golfos. Y queda firme la Opinion que seguimos de S. Efren, que en aquel Continente a vista del Paraiso, aunque fuera del vivieron los hombres hasta el Diluvio: que con su inundación pereciendo todos escepto Noé y su familia, le pasó Dios en el Arca a este, trocandose las calidades de los dos. Este desde entonces se vió poblado, no habiéndolo estado antes: aquel quedó hiermo y solitario, hasta que despues de muchos siglos, entraron en él las gentes que hallaron los Españoles; sin que en el tiempo intermedio le hayan habitado otras. (I, p. 278) 25
La segunda población del Nuevo Mundo presenta menos dificultades. Desde el Diluvio universal al nacimiento de Cristo este continente estuvo despoblado, de modo que vuelven a salir a la luz el tema de las profecías de Isaías sobre la entrada del Evangelio en América y el del origen de los indios. Como esta última cuestión ya había sido tratada con anterioridad, se limita a resumirla. En este punto, al final de la argumentación del Libro segundo, sólo le queda el escolio de la profecía de Isaías, pero basta con interpretar Oriente como Occidente, mecanismo que se repite a lo largo del libro:

Y si bien algunos entienden estas palabras de la Yndia Oriental muchas las explican del Nuevo Mundo, y le convienen mejor. En que los ángeles veloces son los Predicadores Evangelicos. La Gente convulsa, maltratada y terrible los Yndios. Despues de cuya no hai otra, porque despues deste Continente no hay mas que aquel. Gente que aguardaba la Luz del Evangelio entre el cautiverio de la Ydolatria que la tenía destruida y acabada. Y cuya Tierra se halla cortada y dividida de los mayores Ríos que se conocen en el Universo. (I, p. 290) ${ }^{26}$

De lo expuesto en el Libro segundo deriva su teoría, exenta de cualquier aparato científico y expuesta como verdad irrefutable, de que América es el Continente del Paraíso. En la segunda parte, que constituye el cuerpo y adorno de su obra, las cualidades "peregrinas» de las Indias corroboran la tesis enunciada en la primera, componiendo una enciclopedia entre científica y maravillosa de su riqueza y magnificencia. Al acabar su libro, Antonio de León Pinelo ha demostrado que a la Ibérica Meridional convienen todas las calidades y circunstancias del Paraíso Terrenal y, lleno de orgullo, concluye:

Al fin en secreto que lo ha sido a la experiencia de tantos Siglos, al discurso de tantos Ingenios, al vuelo de tan delgadas plumas, a la exposición de tantos doctores, y al sentir de tantos Santos: ¿quién se atreverá a afirmar lo que apenas se puede percibir? (II, p. 532)

León Pinelo no mira hacia delante, no sitúa el Jardín del Edén en el futuro, sino en una América primigenia. Con los ojos vueltos hacia el pasado, mira hacia un Paraíso encontrado pero irremediablemente perdido. 